\title{
The Estimation of Chemical Oxygen Demand of Erhai Lake Basin and Its Links with DOM Fluorescent Components Using Machine Learning
}

\author{
Yuquan Zhao ${ }^{1,2}$, Jian Shen $1,2,3, * \mathbb{C}$, Jimeng Feng ${ }^{1,2,3}$, Zhitong Sun ${ }^{4}$, Tianyang Sun ${ }^{2,3}$, Decai Liu ${ }^{2,3}$, Mansong $\mathrm{Xi}^{5}$, \\ Rui Li ${ }^{6}$ and Xinze Wang ${ }^{1,2,3, *}$ \\ 1 School of Environmental Science and Engineering, Shanghai Jiao Tong University, Shanghai 200240, China; \\ zhaoyuquan@sjtu.edu.cn (Y.Z.); fjm520@sjtu.edu.cn (J.F.) \\ 2 National Observation and Research Station of Erhai Lake Ecosystem in Yunnan, Dali 671000, China; \\ suntianyang_139872@163.com (T.S.); dcliu86@163.com (D.L.) \\ 3 Yunnan Dali Research Institute of Shanghai Jiao Tong University, Dali 671000, China \\ 4 Institute of Water Resource Sciences, Northwest Agriculture and Forestry University, Xianyang 712100, China; \\ sunnyzt@nwafu.edu.cn \\ 5 Dali Erhai Lake Research Institute, Dali 671000, China; xiweng@foxmail.com \\ 6 Yunnan Institute of Water \& Hydropower Engineering Investigation, Design and Research, \\ Kunming 650233, China; Ir1909@163.com \\ * Correspondence: sjlnts@sjtu.edu.cn (J.S.); xinzewang@sjtu.edu.cn (X.W.)
}

Citation: Zhao, Y.; Shen, J.; Feng, J.; Sun, Z.; Sun, T.; Liu, D.; Xi, M.; Li, R.; Wang, $X$. The Estimation of Chemical Oxygen Demand of Erhai Lake Basin and Its Links with DOM Fluorescent Components Using Machine Learning. Water 2021, 13, 3629. https://doi.org/10.3390/w13243629

Academic Editor: Matthew P. Miller

Received: 2 November 2021

Accepted: 15 December 2021

Published: 16 December 2021

Publisher's Note: MDPI stays neutral with regard to jurisdictional claims in published maps and institutional affiliations.

Copyright: () 2021 by the authors. Licensee MDPI, Basel, Switzerland. This article is an open access article distributed under the terms and conditions of the Creative Commons Attribution (CC BY) license (https:// creativecommons.org/licenses/by/ $4.0 /)$.

\begin{abstract}
Water quality estimation tools based on real-time monitoring are essential for the effective management of organic pollution in watersheds. This study aims to monitor changes in the levels of chemical oxygen demand (COD, CODMn) and dissolved organic matter (DOM) in Erhai Lake Basin, exploring their relationships and the ability of DOM to estimate COD and CODMn. Excitation emission matrix-parallel factor analysis (EEM-PARAFAC) of DOM identified protein-like component (C1) and humic-like components (C2, C3, C4). Combined with random forest (RF), maximum fluorescence intensity (Fmax) values of components were selected as estimation parameters to establish models. Results proved that the COD of rivers was more sensitive to the reduction in $\mathrm{C} 1$ and C2, while CODMn was more sensitive to C4. The DOM of Erhai Lake thrived by internal sources, and the relationship between COD, CODMn, and DOM of Erhai Lake was more complicated than rivers (inflow rivers of Erhai Lake). Models for rivers achieved good estimations, and by adding dissolved oxygen and water temperature, the estimation ability of COD models for Erhai Lake was significantly improved. This study demonstrates that DOM-based machine learning can be used as an alternative tool for real-time monitoring of organic pollution and deepening the understanding of the relationship between COD, CODMn, and DOM, and provide a scientific basis for water quality management.
\end{abstract}

Keywords: water quality estimation; machine learning models; random forest; EEM-PARAFAC; DOM; COD; CODMn

\section{Introduction}

With the acceleration of the industrialization process, the problem of organic pollution in receiving river basins has become increasingly prominent $[1,2]$. Organic pollution to Erhai Lake Basin, a local drinking water source, has caused deterioration of the aquatic ecosystem and poses a threat to human health [3]. Therefore, continuous water quality monitoring and evaluation for organic matter are essential for rapid pollution control, to ensure the reliability of drinking water, and to help understand the ecosystem functioning of the basin. Traditionally, chemical oxygen demand (COD and CODMn) tests are widely used to determine the organic content of watersheds [4]. The main difference between COD and CODMn test methods lies in the oxidant. COD uses potassium dichromate as 
the oxidant, while CODMn uses potassium permanganate, but both methods demand high-quality personnel, expensive or poisonous reagents, and long analysis time, limiting their application for rapid continuous safety monitoring [5-7].

Recently, fluorescence technology has introduced a wide prospect of applications in the field of hydrological monitoring, due to the small amount of sample required, fast analysis speed, and pollutant-free analysis [8,9]. Excitation emission matrix-parallel factor analysis (EEM-PARAFAC) has been found effective in reflecting the composition and source of dissolved organic matter (DOM), but its application in the estimation of water quality parameters in human affected basins has not been fully explored [10-13]. In addition, understanding the relationship between COD, CODMn, and DOM is helpful to provide a basis for water quality management. Past studies have shown a direct relationship between DOM, COD, and CODMn, which indicates that DOM may be used as a COD and CODMn estimation tool in hydrological monitoring $[14,15]$.

Clarifying the contribution of DOM components to COD and CODMn is conducive to the proposal of scientific water quality management measures, but due to the spatial and temporal heterogeneity and dynamic nature of COD and CODMn in Erhai Lake Basin, traditional regression methods can have difficulties considering the non-linear relationship, which may exist between COD, CODMn and DOM [16]. To capture non-linear relationships that are common in environmental processes, machine learning has recently begun to be used for hydrological monitoring, since it includes algorithms and models that can provide multivariate, nonlinear, nonparametric regression or classification methods [17]. In addition, machine learning models can be trained for several key environmental quality parameters and the final environmental outcomes, using the current archived data, and can further predict future results after inputting new parameters [18]. This shows the potential of using DOM to quickly predict COD and CODMn on site. The study by Peterson et al. (2018) in the Missouri-Mississippi River system proved that machine learning models outperform regression models in predicting water quality parameters, which will help to improve the reliability of estimated COD and CODMn data [19].

Erhai Lake is the second-largest freshwater lake in southwestern China and is an important source of drinking water, irrigation, tourism, and fisheries for Dali (Yunnan, China) [20]. Therefore, understanding the dynamic changes of organic matter content and realizing the real-time monitoring of COD and CODMn are of great significance for the water quality management of Erhai Lake Basin. Herein, we collected 651 water samples from the Erhai Lake Basin in 12 months, used EEM-PARAFAC to obtain the main components of DOM and the maximum fluorescence intensity (Fmax) of each component. Using machine learning algorithms, we trained and modeled the gained data sets. The aims of this study were to (1) analyze seasonal changes of COD, CODMn, and DOM in Erhai Lake Basin; (2) compare the difference in the contribution of different DOM fluorescent components to COD and CODMn; (3) test the ability of DOM to estimate COD and CODMn.

\section{Material and Methods}

\subsection{Study Area and Sample Collection}

The Erhai Lake Basin is located in the watershed of the major water system of Lancang River in Yunnan Province, China (Figure 1), with a drainage area of approximately $2565 \mathrm{~km}^{2}$ [21]. The basin is located in a plateau in a subtropical monsoon climate zone, with an average annual rainfall of $858 \mathrm{~mm}$ and a mean annual air temperature of $18.1^{\circ} \mathrm{C}$. Erhai Lake $\left(25^{\circ} 47^{\prime} \mathrm{N}, 100^{\circ} 11^{\prime} \mathrm{E}\right)$ is the second-largest freshwater lake in Yunnan Province, with an area of approximately $250 \mathrm{~km}^{2}$ and a water depth of $10.2 \mathrm{~m}$ [21].

In this study, the water samples were collected from Erhai Lake and its main 27 inflow rivers, with annual runoff accounting for $95 \%$ of the total river flow into the lake. A total of 19 sampling points were set in the lake, and 27 sampling points were set at river mouths running into the lake (Figure 1). For the lake, surface water samples $(0.5 \mathrm{~m}$ from the surface) and bottom water samples ( $0.5 \mathrm{~m}$ from the bottom) were collected. For rivers, surface 
samples (0.2 $\mathrm{m}$ from the surface) were collected [22,23]. Water samples were collected monthly in 2020 ( 65 sites, provided that the rivers were not dried up). Water temperature (WT) and $\mathrm{pH}$ were measured with HACH HQ40d, and different portable dissolved oxygen meters (YSI550A, Yellow Springs, OH, USA) were used for the measurement of dissolved oxygen (DO). Water samples were collected with a LIMNOS water sampler and were temporarily stored in $1 \mathrm{~L} \mathrm{PVC} \mathrm{bottles.} \mathrm{The} \mathrm{water} \mathrm{sample} \mathrm{was} \mathrm{first} \mathrm{sieved} \mathrm{(250} \mathrm{mesh)} \mathrm{and}$ then placed in an HPDE container that was preliminarily soaked in $0.1 \mathrm{~mol} \mathrm{~L}^{-1} \mathrm{HCL}$ for $24 \mathrm{~h}$ and rinsed with Milli-Q water (Millipore Co., Bedford, MA, USA). The determination of all indicators was completed within $24 \mathrm{~h}$.

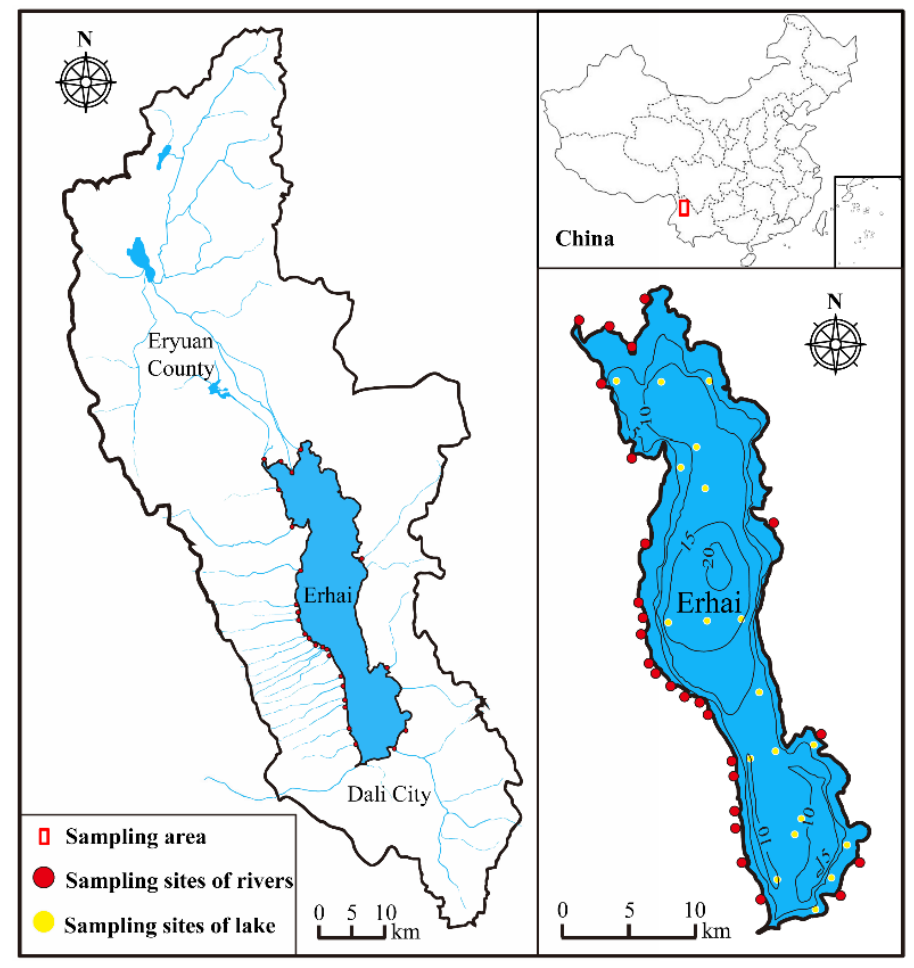

Figure 1. Study area and sampling sites.

\subsection{Analytical Measurements}

\subsubsection{Water Quality Index}

COD was determined following the potassium dichromate index method [24]. CODMn was analyzed by the potassium permanganate index method [25]. Total nitrogen (TN) and ammonia $\left(\mathrm{NH}_{4}-\mathrm{N}\right)$ concentrations were determined by alkaline potassium persulfate digestion-UV spectrophotometric method (The Chinese National Standard HJ6362012) [26]. The dissolved organic nitrogen (DON) concentration is the value obtained by subtracting the dissolved inorganic nitrogen from the total dissolved nitrogen [26]. Total phosphorus (TP) and orthophosphate concentrations were measured by using the ammonium molybdate spectrophotometric method (The Chinese National Standard GB11893-89) [27]. Water for Chlorophyll a (Chla) was first filtered through a $0.45 \mu \mathrm{m}$ glass fiber membrane, and then, the sample membrane was extracted with $90 \%$ acetone for $24 \mathrm{~h}$ and measured colorimetrically [28].

\subsubsection{DOM Measurements and Analyses}

Before the measurement, a pre-burned $\left(500^{\circ} \mathrm{C}, 4 \mathrm{~h}\right)$ Whatman GF/F glass fiber filter (GE Healthcare, Pittsburgh, PA, USA) was used to preliminarily filter the water samples; then, a $0.45 \mu \mathrm{m}$ glass fiber membrane rinsed with ultrapure water was used to further filter the water samples. The filtered water samples were stored in a brown glass bottle. The measurement was completed within $24 \mathrm{~h}$. 
In order to build excitation-emission matrices (EEMs), the measurement of the fluorescence intensity was carried out in a fluorescence spectrophotometer (RF-6000, Japan), across excitation wavelengths ranging from 260 to $400 \mathrm{~nm}$ ( 2 nm increments) and emission wavelengths ranging from 300 to $600 \mathrm{~nm}$ ( $1 \mathrm{~nm}$ increment). Bandpass was set at $5 \mathrm{~nm}$, and the scanning speed was $6000 \mathrm{~nm} / \mathrm{min}$. Milli-Q ultrapure water was used to calibrate the three-dimensional fluorescence spectrum of the sample, thereby reducing the influence of instrument and Raman scattering [29]. The fluorescence data were used to calculate the fluorescent index $(\mathrm{FI})$, freshness index $(\beta / \alpha)$, humification index (HIX), and spontaneous source index (BIX) (Table S1) [8,12,30-32].

PARAFAC can decompose the matrix data of the three-dimensional fluorescence spectrum into discrete variables to obtain the main components in the complex mixtures of DOM fluorophores [9]. This study was based on the method of Stedmon and Bro (2008), using the DOMFlour toolbox to carry out the analysis in MATLAB R2020a (The MathWorks, Inc., Natick, MA, USA) [33]. The inner-filter effects were corrected by the formula reported by Larsson et al. (2007) [34]. EEMs were normalized before model validation, and the appropriate number of components was verified by split-half analysis and random initialization, as suggested by Murphy et al. (2013) [35]. Split-half validation was performed on 4-, 5-, 6-, and 7-component models, and the 4-component model was validated, while others were not. The PARAFAC analysis finally separated the multiple fluorescence components and their respective maximum fluorescence intensity (Fmax). The Sum of Fmax (SOF) for C1-C4 was used to indicate the total fluorescence of the DOM sample. The final results of DOM components were further uploaded to the OpenFluor network (https:/ / openfluor.lablicate.com/, accessed on 6 June 2021), and the criteria for matching components were set at 95\% similarity and assessed through Tucker's Congruence Coefficient [36].

\subsection{Machine Learning}

COD, CODMn, and the Fmax values of DOM components were trained by random forest (RF). RF is a machine learning algorithm for classification and regression that consists of a set of decision trees [37]. In RF regression, it first extracts bootstrap samples from the original data and then generates regression trees by using the classification and regression tree (CART) [38]. After the best split on each node is completed, multiple estimations on target variables are produced. By voting them, we obtain a final output $[37,39]$. As one of the well-known machine learning algorithms, RF has the advantages of high estimative performance, the ability to capture the nonlinear dependencies between predictor and dependent variables, and the ability to handle highly correlated predictor variables [40-42].

RF models were constructed through Anaconda 3 (v5.2.0) (Anaconda Inc., Austin, TX, USA), and the program code was written by Python programing language. In this study, $80 \%$ of randomly selected data were used in the training phase of the model, and the other $20 \%$ examined the model performance. The RandomForestRegressor function of the library Scikit-Learn was used to build estimative models. Using the GridSearchCV function from the Scikit-Learn library, a grid search was implemented to gain a set of the ideal value of the parameters (Table S2). Then, fivefold cross validation (CV) was used to establish and validate the estimation results (Figure S1). The entire training data set was randomly divided into 5 subsets, 4 of which were used for model training and to make estimations for the subsets not involved in training. The whole process was repeated 5 times until each subset was tested [37]. Further, R square $\left(R^{2}\right)$, root-mean-squared error (RMSE), and residual estimation deviation $(R P D)$ were calculated to judge the generalizing capability of the model [43]. If the RPD value was greater than 2, the model was considered to be a stable and accurate estimative model, while a value between 1.4 and 2 indicated that the model had a certain estimative ability but still had room for improvement; a value less than 1.4 indicated that the model had almost no estimative ability [44]. 
In this study, we followed the following steps for data analysis and modeling:

1. Firstly, EEM-PARAFAC was used to analyze the water samples of the Erhai Lake Basin and identify the main DOM components. The seasonal differences in the COD, CODMn, DOM components, and the fluorescence index of the rivers and Erhai Lake were explored. The four seasons in this study were defined as spring (February-April), summer (May-July), autumn (August-October), and winter (November-January of next year).

2. Secondly, RF was used to train the Fmax values of DOM components and corresponding COD and CODMn data. Considering that there may be differences between rivers and Erhai Lake, the models were established separately [15].

3. Thirdly, using RF, the Fmax of each component of the DOM would be sequentially reduced (Fmax was reduced in steps of 10\% until it became 0) for COD and CODMn estimation. This was to explore the differences in the effects of DOM components on COD and CODMn.

4. Finally, the effectiveness of adding new environmental variables to the models in improving the prediction ability of COD and CODMn was explored.

\subsection{Other Statistical Analysis}

By using SPSS Statistics 26.0 software (IBM Corp., Armonk, NY, USA), Pearson's correlation analysis was used to evaluate the correlation between the parameters, and one-way ANOVA (analysis of variance) was used for each variable to determine if the differences in the means between sampling depths were statistically significant. Significant correlations in the statistics were evaluated using $p$ values. The descriptive statistics and graph production of the data were carried out in origin 2020b and ArcGIS 10.8.

\section{Results and Discussion}

\subsection{Seasonal Changes of COD, CODMn, and DOM}

Using PARAFAC, we identified four DOM components in Erhai Lake Basin-one protein-like component (C1) and three humic-like components (C2, C3, and C4) (Figure S2, Table S3). The one-way ANOVA test showed that there was no significant variation in each variable among different depths $(p>0.05)$ (Table S4); thus, for all variables, the average values of surface water and bottom water are discussed in this section (Table S5).

With the arrival of summer, $\mathrm{C} 1$ reached its peak in the lake (Figure 2). This has been associated with an increase in biological activity in summer, which promotes the increase in the protein-like component [45]. The spatial distribution of DOM in summer suggested that $\mathrm{C} 1$ was more internally affected (Figure S3). For example, $\mathrm{C} 1$ values in the middle sampling sites (2 and 18) were higher than that of the sampling sites $(1,11,12,13$, and 14) near the river mouth. This was consistent with the endogenous influence indicated by FI, which reached the highest value in summer. The relative abundance of humic-like substances in the rivers reached the highest value in summer, which was similar to the results of previous studies in temperate rivers and related to the rainfall $[46,47]$. The mean annual rainfall of Erhai Lake Basin is $858 \mathrm{~mm}$, of which $90 \%$ falls in the wet season between May and October [20]. Studies have shown an increased abundance of humus components of DOM following rainstorm events, as more rainfall in summer may promote the release of soil organic matter into the river and terrestrial plants in the form of humus substances $[48,49]$. In addition, the SOF of the lake was on an upward trend throughout the year, while that of the rivers began to decline after reaching a peak in summer (Figure S4). This indicated that after summer, the DOM level in the Erhai Lake was not mainly controlled by the rivers. Combined with the FI value of Erhai Lake, close to 1.8 instead of 1.4, we believe that the DOM of Erhai Lake thrived by internal sources (extracellular release and leachate from bacteria and algae). 

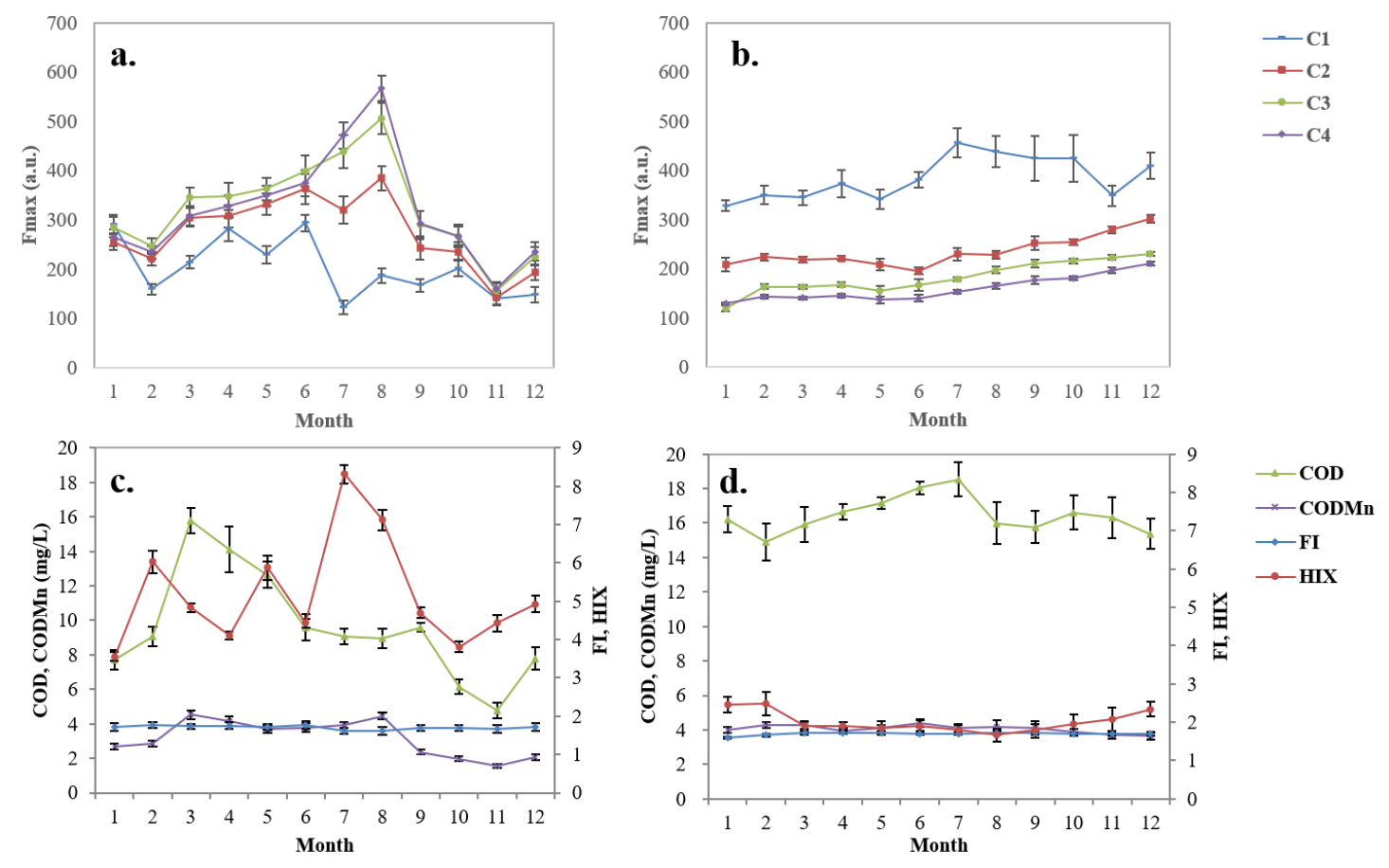

Figure 2. Mean values of DOM, COD, and CODMn in 2020: (a,c) rivers; (b,d) Erhai Lake.

COD and CODMn have been widely used to evaluate organic content in water systems [50,51]. Similar to other lakes in China, our results showed that COD and CODMn of the lake reached their peak in summer, which may be related to phytoplankton detritus and the release of dissolved organic matter from phytoplankton [52-55]. Although the humic-like components in rivers reached their peak in summer, COD and CODMn had a certain degree of decline, compared with spring, and the downward trend of COD was more obvious. The protein-like component may contribute to more COD. Therefore, with the decrease in $\mathrm{C} 1$ in summer, $\mathrm{COD}$ was also reduced to a certain extent. In addition, the amount of water brought in summer may have diluted the concentration of organic matter in the river to a certain extent so as to reduce COD [56]. Although both COD and CODMn were indirect expressions of the oxidation degree of organic matter, the correlation between COD and CODMn in rivers was obviously stronger than that in Erhai Lake (Tables S6 and S7). COD measured by the potassium dichromate method can express most of the reducing substances in the water body and oxidation rate can reach $90 \%$, while the CODMn value obtained based on the potassium permanganate method can only reflect some reducing substances that were easily oxidized [57-59]. Therefore, a lower correlation means there were more complex substances that were not easily oxidized in the water body. These results indicated that the organic matter in the Erhai Lake may be more complex and include more substances not easy to be oxidized by potassium permanganate. The correlation results of DOM, COD, and CODMn were also quite different in the rivers and Erhai Lake. COD, CODMn, and DOM components had a good correlation in rivers. Correlation coefficients were all greater than 0.6 , in which the correlation coefficients of humic-like components, and CODMn were all greater than 0.8 , indicating that the humic-like components and CODMn had a close relationship in the rivers. There was no strong positive correlation (correlation coefficient $>0.6$ ) between COD, CODMn, and DOM in Erhai Lake. In summer, there were high COD and CODMn values in the north of Erhai Lake, while humic-like components $(\mathrm{C} 2, \mathrm{C} 3$, and $\mathrm{C} 4)$ were mainly concentrated in the south, and the protein-like component (C1) was widely distributed in the whole lake (Figure S4). These results implied that relying on DOM to estimate COD and CODMn in the lake may have poor accuracy. 


\subsection{Performance of Models and Variable Importance}

A Pearson's correlation analysis was performed on all variables (Tables S6 and S7). The results showed that the DOM components $(\mathrm{C} 1, \mathrm{C} 2, \mathrm{C} 3$, and $\mathrm{C} 4)$ had a significant positive correlation with each other, which indicated that there may be a potential multicollinearity problem between the independent variables. This was one of the reasons why we chose $\mathrm{RF}$ to build the model because it had been proved that this machine learning method was equally applicable to highly correlated variables [60,61].

The RF model has been widely used in the estimation of water quality indicators in recent years and has been proven to have good estimative capabilities [62]. $R P D$ values of river models were generally greater than 2 , which showed that they had a good estimation of COD and CODMn in rivers, while RPD values in lake models were between 1.4 and 2, which showed that they had a certain estimation ability for COD and CODMn (Figure 3). CODMn model of rivers (CODMn-R) had a higher $R^{2}$ value and smaller RMSE value than the COD model of rivers (COD-R), which proved that the estimation error of CODMn$\mathrm{R}$ was less. $\mathrm{RF}$ is an ensemble learning model optimized on the basis of traditional learning models [63]. By integrating the results of multiple independent decision trees and estimating a result, the final result will be better than the calculation result of a single tree [64]. The results proved that RF models based on fluorescent components were effective for estimating COD and CODMn in rivers and had certain estimation ability for COD and CODMn in Erhai Lake, which revealed the development potential of DOM fluorescence intensity in the estimation of water quality indicators. As a nonlinear model, RF results showed that DOM tends to be nonlinear with COD and CODMn in Erhai Lake Basin [41]. In addition, it showed that the source of COD and CODMn in Erhai Lake was more complicated than that of rivers, and it was not enough to estimate COD and CODMn of Erhai Lake rely on DOM alone, which was consisted with weak correlation results of COD, CODMn and DOM in the lake.
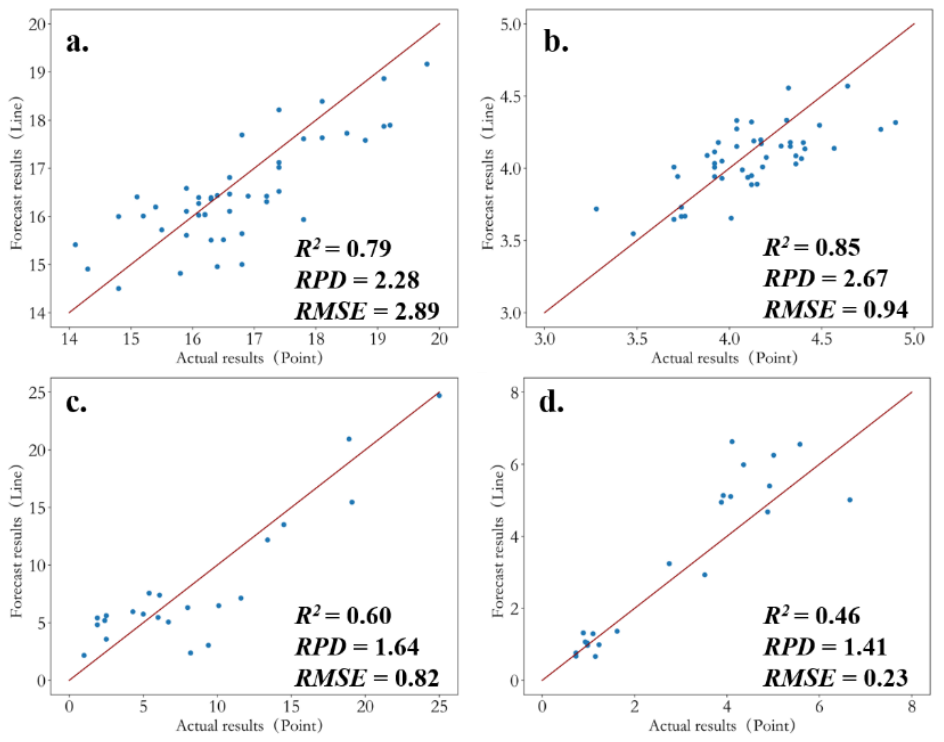

Figure 3. Test results of the RF models: (a) COD model of rivers (COD-R); (b) CODMn model of rivers (CODMn-R); (c) COD model of lake (COD-L); (d) CODMn model of lake (CODMn-L).

Since river models showed better estimation ability, we reduced the Fmax of DOM and substituted it into the river models to obtain the difference in the contribution of DOM components to COD and CODMn (Figure 4, Tables S8 and S9). Overall, with the decrease in Fmax of the DOM components, the level of COD and CODMn decreased correspondingly. For COD models (Figure $4 \mathrm{a}-\mathrm{d}$ ), when the reduction level was $100 \%$, the results of $\mathrm{C} 1$ and C2 were similar, that is, $\mathrm{C} 1$ and $\mathrm{C} 2$, respectively, led to a $29 \%$ and $26 \%$ drop in COD concentration. This was consistent with the close relationship of $\mathrm{C} 1, \mathrm{C} 2$, and COD in the 
correlation results. The influence of C3 and C4 was relatively small, but that of C4 (14\%) was greater than that of C3 (6\%). In the CODMn models (Figure 4e-h), C4 had the greatest impact. When C4 was completely removed, CODMn was reduced by $16 \%$. When the reduction degree was $100 \%$, the reduction degree of CODMn corresponding to $\mathrm{C} 1, \mathrm{C} 2$, and C3 was $4 \%, 6 \%$, and $6 \%$, respectively.
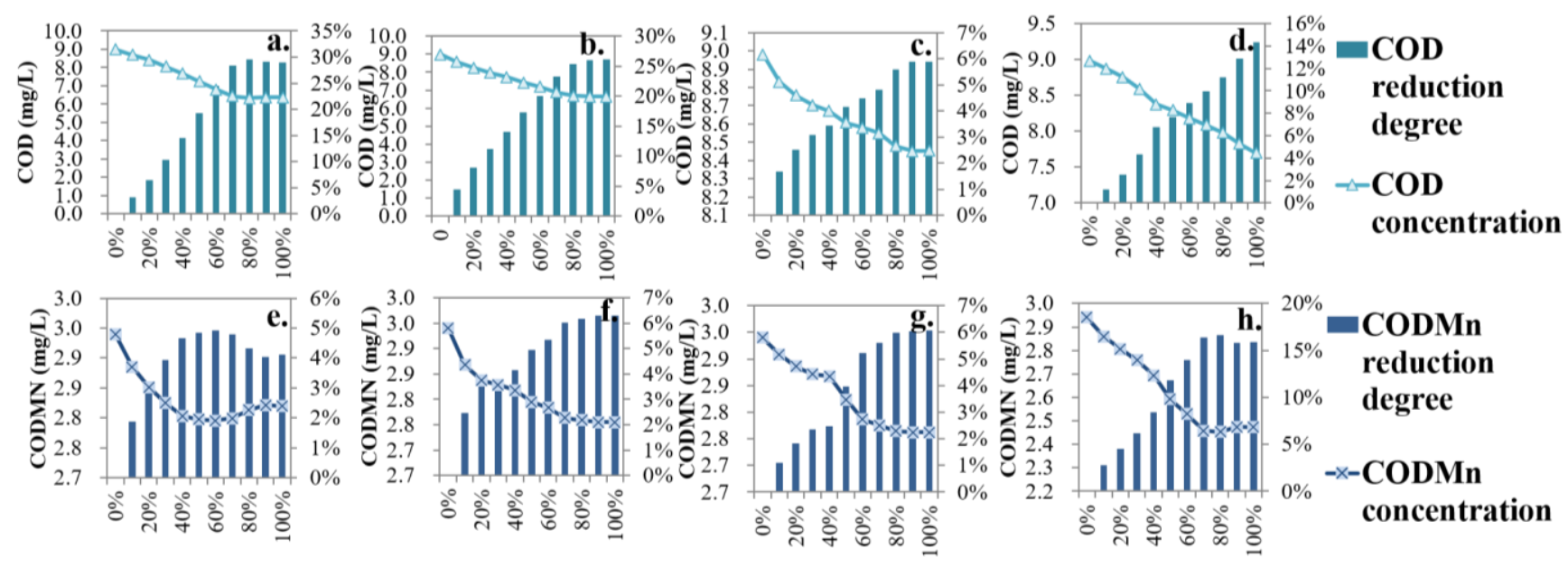

Figure 4. COD and CODMn response curve of DOM's Fmax reduction: (a) C1 of rivers; (b) C2 of rivers; (c) C3 of rivers; (d) C4 of rivers; (e) C1 of lake; (f) C2 of lake; (g) C3 of lake; (h) C4 of lake.

Machine learning methods have been increasingly used in hydrological monitoring in recent years. The results of this study showed an obvious advantage of RF in considering nonlinear relationships and the effectiveness of RF in COD and CODMn prediction. This will be beneficial to the real-time monitoring of organic pollution in Erhai Lake Basin as COD and CODMn can be obtained through the real-time calculation of machine learning models. The results also promoted the understanding of the relationship between COD, CODMn, and DOM. C1 and C2 have a greater impact on COD and less on CODMn, which may indicate that these two components contain substances that were not easily oxidized by potassium permanganate. Past studies have suggested that protein substances were more difficult to degrade than humus substances, which may explain the difference in protein-like component $\mathrm{C} 1$ in different models [65]. C2 was identified as a refractory humic-like component, with a high aromatization degree and complex structure [66,67]. This may make it less susceptible to oxidation by potassium permanganate. In the past, $\mathrm{C} 4$ was recognized as resembling plant-derived humus. CODMn was most sensitive to the reduction in $\mathrm{C} 4$, which suggested that $\mathrm{C} 4$ may be easily oxidized by potassium permanganate $[68,69]$. The results showed that COD was more sensitive to the reduction in $\mathrm{C} 1$ and $\mathrm{C} 2$, while CODMn was more sensitive to the reduction in $\mathrm{C} 4$, which suggested that we should pay attention to the change in $\mathrm{C} 1, \mathrm{C} 2$, and $\mathrm{C} 4$ and reduce their concentration in water to prevent possible organic pollution in Erhai Lake Basin.

\subsection{Optimization of Estimation Models in Erhai Lake}

Although the COD and CODMn models based on DOM in Erhai Lake had certain estimative capabilities, compared with rivers, their estimation ability was poor. We adopted the concept of using additional indicators $\left(\mathrm{WT}, \mathrm{DO}, \mathrm{pH}, \mathrm{TN}, \mathrm{DON}, \mathrm{NH}_{4}-\mathrm{N}, \mathrm{TP}\right.$, orthophosphate, and Chla) with the RF method to upgrade the accuracy of model estimation, as this method has been proven effective [70]. For COD, the addition of WT made the model stable and accurate $(R P D$ value $>2)$, the addition of orthophosphate and $\mathrm{NH}_{4}-\mathrm{N}$ improved the prediction ability of models $(1.4<R P D$ value $<2)$ (Table 1$)$. Although orthophosphate and $\mathrm{NH}_{4}-\mathrm{N}$ cannot be oxidized by potassium dichromate or potassium permanganate, our results may suggest that they can indirectly reflect the level of organic matter in the water. For CODMn, the addition of indicators improved the estimative ability to a certain 
extent, it did not exceed 2 overall. This showed that for Erhai Lake, it was difficult to construct CODMn estimative models with general water quality indicators, and further research is needed.

Table 1. Results of RF models.

\begin{tabular}{ccccccc}
\hline \multirow{2}{*}{ Add Indicator } & \multicolumn{3}{c}{ L-COD } & \multicolumn{3}{c}{ L-CODMn } \\
\cline { 2 - 7 } & $\boldsymbol{R}^{\mathbf{2}}$ & $\boldsymbol{R P D}$ & $\boldsymbol{R M S E}$ & $\boldsymbol{R}^{\mathbf{2}}$ & $\boldsymbol{R P D}$ & $\boldsymbol{R} \boldsymbol{M S E}$ \\
\hline WT & 0.74 & 2.03 & 0.66 & 0.53 & 1.51 & 0.22 \\
DO & 0.67 & 1.81 & 0.74 & 0.50 & 1.46 & 0.23 \\
pH & 0.64 & 1.73 & 0.77 & 0.53 & 1.52 & 0.22 \\
TN & 0.60 & 1.63 & 0.82 & 0.42 & 1.36 & 0.24 \\
DON & 0.63 & 1.70 & 0.79 & 0.48 & 1.44 & 0.23 \\
NH $_{4}$-N & 0.69 & 1.86 & 0.72 & 0.53 & 1.50 & 0.22 \\
TP & 0.63 & 1.71 & 0.78 & 0.51 & 1.47 & 0.22 \\
Orthophosphate & 0.66 & 1.77 & 0.75 & 0.54 & 1.53 & 0.21 \\
Chla & 0.66 & 1.77 & 0.75 & 0.47 & 1.43 & 0.23 \\
WT, DO & 0.77 & 2.14 & 0.62 & 0.57 & 1.57 & 0.21 \\
WT, pH & 0.75 & 2.09 & 0.64 & 0.55 & 1.53 & 0.21 \\
DO, pH & 0.71 & 1.92 & 0.70 & 0.54 & 1.53 & 0.21 \\
WT, DO, pH & 0.75 & 2.06 & 0.65 & 0.56 & 1.55 & 0.21 \\
\hline
\end{tabular}

Compared with other indicators, $\mathrm{DO}, \mathrm{pH}$, and $\mathrm{WT}$ have the advantages of easy access and no pollution. Therefore, we tried to combine these three indicators with DOM to further improve the model. Results showed the combination of DO and WT can further optimize the COD and CODMn models since their RPD values reached the highest in L-COD and L-CODMn, respectively. This may be because both can affect COD and CODMn through regulating chemical reactions, as well as biological physiology. For example, the increase in WT may lead to an increase in phytoplankton abundances, which can release organic matter into the water body [71]. A study by Marcinek et al. (2020) showed the production of organic matter is linearly related to oxygen consumption in hypoxic waters [72]. The results of this study showed the close relationship between DO, WT, COD, and CODMn and suggested the importance of choosing appropriate parameters in establishing machine learning models.

\section{Conclusions}

Herein, we adopted RF to estimate COD and CODMn in the Erhai Lake Basin based on DOM components. The Fmax of DOM, COD, and CODMn for 12 months in 2020 was put into models for training. Next, we reduced the Fmax of DOM proportionally and put it into the models for COD and CODMn estimation. We compared and analyzed the differences in the contribution of different components. Finally, we attempted to add new variables to improve the estimation ability of models. The major findings of this study are listed as follows:

1. The DOM of Erhai Lake thrived by internal sources (extracellular release and leachate from bacteria and algae);

2. The aquatic ecosystem of Erhai Lake is more complicated than rivers. In Erhai Lake, the correlation between COD, CODMn, and DOM components and the estimative ability of COD and CODMn models based on DOM were not as good as that of rivers;

3. There were differences in the contribution of DOM components to COD and CODMn. COD was more sensitive to the reduction in $\mathrm{C} 1$ and $\mathrm{C} 2$, while CODMn was more sensitive to the reduction in $\mathrm{C} 4$;

4. The selection of appropriate environmental variables will help improve the accuracy of RF models. DO and WT were considered to be the best indicators to improve the accuracy of the COD and CODMn estimation models in Erhai Lake; 
5. As an integrated learning model composed of multiple learning, RF showed an advantage to consider nonlinear relationships between COD, CODMn, and DOM, which proved its potential in hydrological monitoring.

The RF model showed accurate training and validation results for the estimation of COD and CODMn. This can reduce the experimental cost and time. Through an in-depth understanding of seasonal changes in COD, CODMn, and DOM, the differences in the contribution of DOM components to COD and CODMn, which were conducive to taking targeted response measures to potential organic pollution, so as to create a better water quality ecological environment. Our research showed the potential of DOM and machine learning in constructing water quality estimation models. In the future, we propose to invest a wider range of monitoring data into existing models to improve stability and apply more water quality index estimation models to the pollution assessment system of the aquatic environment to reduce testing costs, speed up testing time, and avoid potential pollutants problems.

Supplementary Materials: The following are available online at https:/ /www.mdpi.com/article/10 $.3390 / w 13243629 /$ s1, Figure S1. The sketch map of 5-fold cross validation. Figure S2. PARAFAC model output showing fluorescence signatures of the four DOM components. Figure S3. Spatial distribution of COD, CODMn and DOM in Summer. a: C1; b: C2; c: C3; d: C4; e: COD; f: CODMn. Figure S4. Sum of Fmax for C1-C4. Table S1. Spectral parameter description. Table S2. Values of the parameters contained in the grid search. Table S3. Characteristics of four PARAFAC components. Table S4. Seasonal Changes of COD, CODMn and DOM. Table S5. ANOVA of variables. Table S6. Correlation coefficient of COD, CODMn and DOM in rivers. Table S7. Correlation coefficient of COD, CODMn and DOM in lake. Table S8. COD response of DOM's Fmax reduction. Table S9. CODMn response of DOM's Fmax reduction.

Author Contributions: Conceptualization, Y.Z. and J.S.; methodology, Y.Z. and Z.S.; software, Z.S.; validation, Y.Z. and J.S.; investigation, T.S., D.L., M.X. and R.L.; resources, J.F.; data curation, T.S. and Y.Z. writing — original draft preparation, Y.Z.; writing — review and editing, Y.Z. and J.S.; visualization, Y.Z.; supervision, J.S. and X.W.; project administration, J.F.; funding acquisition, J.S., J.F. and X.W. All authors have read and agreed to the published version of the manuscript.

Funding: This research was funded by the Ministry of Ecology and Environment of the People's Republic of China (The Yangtze River Eco-environmental Protection and Restoration Joint Research Project, No. 2019-LHYJ-01-0202-52) and the Bureau of Erhai Lake Management of the Dali Prefecture Government (General Research Fund, No. TPDL-2019-C211-B).

Data Availability Statement: The data sets analyzed during the current study are available from Yunnan Erhai Lake Ecosystem Observation and Research Station, but restrictions apply to the availability of these data, which were used under license from Yunnan Erhai Lake Ecosystem Observation and Research Station and therefore are not publicly available. Data are, however, available from the authors upon reasonable request.

Acknowledgments: The authors would like to acknowledge the support of the client project team and their collaborative effort with the wider project team, which included Yunnan Erhai Lake Ecosystem Observation and Research Station, Yunnan Dali Research Institute of Shanghai Jiao Tong University, Dali Erhai Lake Research Institute, and Yunnan Institute of Water and Hydropower Engineering Investigation, Design, and Research.

Conflicts of Interest: The authors declare they have no conflict of interest.

\section{References}

1. Lefebvre, O.; Moletta, R. Treatment of organic pollution in industrial saline wastewater: A literature review. Water Res. 2006, 40, 3671-3682. [CrossRef] [PubMed]

2. McCabe, K.M.; Smith, E.M.; Lang, S.Q.; Osburn, C.L.; Benitez-Nelson, C.R. Particulate and Dissolved Organic Matter in Stormwater Runoff Influences Oxygen Demand in Urbanized Headwater Catchments. Environ. Sci. Technol. 2021, 55, $952-961$. [CrossRef]

3. Voulvoulis, N.; Arpon, K.D.; Giakoumis, T. The EU Water Framework Directive: From great expectations to problems with implementation. Sci. Total Environ. 2017, 575, 358-366. [CrossRef] [PubMed] 
4. Zhao, Y.; Song, K.; Li, S.; Ma, J.; Wen, Z. Characterization of CDOM from urban waters in Northern-Northeastern China using excitation-emission matrix fluorescence and parallel factor analysis. Environ. Sci. Pollut. Res. 2016, 23, 15381-15394. [CrossRef]

5. Abuzaid, N.S.; Al-Malack, M.H.; El-Mubarak, A.H. Alternative Method for Determination of the Chemical Oxygen Demand for Colloidal Polymeric Wastewater. Bull. Environ. Contam. Toxicol. 1997, 59, 626-630. [CrossRef]

6. Kim, Y.C.; Sasaki, S.; Yano, K.; Ikebukuro, K.; Hashimoto, K.; Karube, I. Photocatalytic sensor for the determination of chemical oxygen demand using flow injection analysis. Anal. Chim. Acta 2001, 432, 59-66. [CrossRef]

7. Saarinen, T.; Vuori, K.-M.; Alasaarela, E.; Kløve, B. Long-term trends and variation of acidity, CODMn and colour in coastal rivers of Western Finland in relation to climate and hydrology. Sci. Total Environ. 2010, 408, 5019-5027. [CrossRef]

8. Cory, R.M.; McKnight, D.M. Fluorescence Spectroscopy Reveals Ubiquitous Presence of Oxidized and Reduced Quinones in Dissolved Organic Matter. Environ. Sci. Technol. 2005, 39, 8142-8149. [CrossRef]

9. Stedmon, C.; Markager, S.; Bro, R. Tracing dissolved organic matter in aquatic environments using a new approach to fluorescence spectroscopy. Mar. Chem. 2003, 82, 239-254. [CrossRef]

10. Coble, P.G.; Green, S.; Blough, N.V.; Gagosian, R.B. Characterization of dissolved organic matter in the Black Sea by fluorescence spectroscopy. Nature 1990, 348, 432-435. [CrossRef]

11. Warner, I.M.; Christian, G.D.; Davidson, E.R.; Callis, J.B. Analysis of multicomponent fluorescence data. Anal. Chem. 1977, 49, 564-573. [CrossRef]

12. Mcknight, D.M.; Boyer, E.; Westerhoff, P.K.; Doran, P.T.; Kulbe, T.; Andersen, D. Spectrofluorometric characterization of dissolved organic matter for indication of precursor organic material and aromaticity. Limnol. Oceanogr. 2001, 46, 38-48. [CrossRef]

13. Morgane, D.; Retelletti, B.S.; Rafael, G.-A. Characterization of aquatic organic matter: Assessment, perspectives and research priorities. Water Res. 2019, 163, 114908.

14. Wang, S.; Zhang, B.; Fu, Z.; Guo, Y.; Jiang, X. Effects of the virgin forests to the dissolved organic matters in small forested watershed: A case study of the Tangwang River in Northeast China. Environ. Sci. Pollut. Res. 2021, 28, 39268-39281. [CrossRef] [PubMed]

15. Yao, X.; Zhang, Y.; Zhu, G.; Qin, B.; Feng, L.; Cai, L.; Gao, G. Resolving the variability of CDOM fluorescence to differentiate the sources and fate of DOM in Lake Taihu and its tributaries. Chemosphere 2010, 82, 145-155. [CrossRef]

16. Zhang, Y.; Pulliainen, J.; Koponen, S.; Hallikainen, M. Application of an empirical neural network to surface water quality estimation in the Gulf of Finland using combined optical data and microwave data. Remote Sens. Environ. 2002, 81, 327-336. [CrossRef]

17. Lary, D.; Alavi, A.H.; Gandomi, A.; Walker, A.L. Machine learning in geosciences and remote sensing. Geosci. Front. 2016, 7, 3-10. [CrossRef]

18. Ghahramani, Z. Probabilistic machine learning and artificial intelligence. Nature 2015, 521, 452-459. [CrossRef] [PubMed]

19. Peterson, K.T.; Sagan, V.; Sidike, P.; Cox, A.L.; Martinez, M. Suspended Sediment Concentration Estimation from Landsat Imagery along the Lower Missouri and Middle Mississippi Rivers Using an Extreme Learning Machine. Remote Sens. $2018,10,1503$. [CrossRef]

20. Ji, N.; Wang, S.; Zhang, L. Characteristics of dissolved organic phosphorus inputs to freshwater lakes: A case study of Lake Erhai, southwest China. Sci. Total Environ. 2017, 601-602, 1544-1555. [CrossRef] [PubMed]

21. Guo, H.; Liu, L.; Huang, G.; Fuller, G.; Zou, R.; Yin, Y. A system dynamics approach for regional environmental planning and management: A study for the Lake Erhai Basin. J. Environ. Manag. 2001, 61, 93-111. [CrossRef] [PubMed]

22. ISO 5667-6:2016. Water Quality—Sampling Part 6: Guidance on Sampling of Rivers and Streams; International Standard Iso: Geneva, Switzerland, 2016.

23. ISO 5667-5:1991. Water Quality—Sampling Part 5: Guidance on Sampling of Drinking Water and Water Used for Food and Beverage Processing; International Standard Iso: Geneva, Switzerland, 1991.

24. Greenberg, A.E.; Trussell, R.R.; Clesceri, L.S.; AWW Association. Standard methods for the examination of water and wastewater: Supplement to the sixteenth edition. Am. J. Public Health Nations Health 2005, 56, 387.

25. Adams, V.D. Water and Wastewater Examination Manual; CRC Press LLC: Boca Raton, FL, USA, 1990.

26. Xu, B.; Li, J.; Huang, Q.; Gong, Q.; Li, L. Impacts of land use patterns and typhoon-induced heavy rainfall event on dissolved organic matter properties in the South Tiaoxi River, China. Environ. Earth Sci. 2016, 75, 632. [CrossRef]

27. Lyu, J.C.; Lin, G.H.; Fan, Z.Y.; Lin, W.X.; Dai, Z. Suitable plant combinations for ecological floating beds in eutrophic subtropical coastal wetlands under different salinities: Experimental evidences. Int. J. Environ. Sci. Technol. 2020, 17, 4505-4516. [CrossRef]

28. Jin, X.C.; Tu, Q.Y. The Standard Methods for Observation and Analysis in Lake Eutrophication; China Environmental Science Press: Beijing, China, 1990. (In Chinese)

29. Murphy, K.R.; Butler, K.D.; Spencer, R.G.M.; Stedmon, C.A.; Boehme, J.R.; Aiken, G.R. Measurement of Dissolved Organic Matter Fluorescence in Aquatic Environments: An Interlaboratory Comparison. Environ. Sci. Technol. 2010, 44, 9405-9412. [CrossRef]

30. Parlanti, E.; Wörz, K.; Geoffroy, L.; Lamotte, M. Dissolved organic matter fluorescence spectroscopy as a tool to estimate biological activity in a coastal zone submitted to anthropogenic inputs. Org. Geochem. 2000, 31, 1765-1781. [CrossRef]

31. Ohno, T. Fluorescence inner-filtering correction for determining the humification index of dissolved organic matter. Environ. Sci. Technol. 2002, 36, 742-746. [CrossRef] [PubMed]

32. Huguet, A.; Vacher, L.; Relexans, S.; Saubusse, S.; Froidefond, J.; Parlanti, E. Properties of fluorescent dissolved organic matter in the Gironde Estuary. Org. Geochem. 2008, 40, 706-719. [CrossRef] 
33. Stedmon, C.A.; Bro, R. Characterizing dissolved organic matter fluorescence with parallel factor analysis: A tutorial. Limnol. Oceanogr. Methods 2008, 6, 572-579. [CrossRef]

34. Larsson, T.; Wedborg, M.; Turner, D. Correction of inner-filter effect in fluorescence excitation-emission matrix spectrometry using Raman scatter. Anal. Chim. Acta 2007, 583, 357-363. [CrossRef]

35. Murphy, K.R.; Stedmon, C.A.; Graeber, D.; Bro, R. Fluorescence spectroscopy and multi-way techniques. PARAFAC. Anal. Methods 2013, 5, 6557-6566. [CrossRef]

36. Murphy, K.R.; Stedmon, C.A.; Wenig, P.; Bro, R. OpenFluor-An online spectral library of auto-fluorescence by organic compounds in the environment. Anal. Methods 2013, 6, 658-661. [CrossRef]

37. Breiman, L. Random Forests. Mach. Learn. 2001, 45, 5-32. [CrossRef]

38. Gislason, P.O.; Benediktsson, J.A.; Sveinsson, J.R. Random Forests for land cover classification. Pattern Recognit. Lett. 2006, 27, 294-300. [CrossRef]

39. Cha, D.; Park, S.; Kim, M.S.; Kim, T.; Hong, S.W.; Cho, K.H.; Lee, C. Prediction of Oxidant Exposures and Micropollutant Abatement during Ozonation Using a Machine Learning Method. Environ. Sci. Technol. 2020, 55, 709-718. [CrossRef]

40. Biau, G.; Scornet, E. A random forest guided tour. TEST 2016, 25, 197-227. [CrossRef]

41. Boulesteix, A.-L.; Janitza, S.; Kruppa, J.; König, I.R. Overview of random forest methodology and practical guidance with emphasis on computational biology and bioinformatics. Wiley Interdiscip. Rev. Data Min. Knowl. Discov. 2012, 2, $493-507$. [CrossRef]

42. Ziegler, A.; Koenig, I.R. Mining data with random forests: Current options for real-world applications. Wiley Interdiscip. Rev. Data Min. Knowl. Discov. 2014, 4, 55-63. [CrossRef]

43. Williams, C. Variables Affecting Near-Infrared Reflectance Spectroscopic Analysis. In Near-Infrared Technology in The Agricultural and Food Industries; CiNii: Tokyo, Japan, 1987; pp. 143-166.

44. Chang, C.-W.; Laird, D.A.; Mausbach, M.J.; Hurburgh, C.R. Near-Infrared Reflectance Spectroscopy-Principal Components Regression Analyses of Soil Properties. Soil Sci. Soc. Am. J. 2001, 65, 480-490. [CrossRef]

45. Amaral, V.; Romera-Castillo, C.; Forja, J. Dissolved Organic Matter in the Gulf of Cádiz: Distribution and Drivers of Chromophoric and Fluorescent Properties. Front. Mar. Sci. 2020, 7, 126. [CrossRef]

46. Fellman, J.B.; Hood, E.; Edwards, R.T.; D'Amore, D.V. Changes in the concentration, biodegradability, and fluorescent properties of dissolved organic matter during stormflows in coastal temperate watersheds. J. Geophys. Res. Space Phys. 2009, 114. [CrossRef]

47. Lee, S.-A.; Kim, G. Sources, fluxes, and behaviors of fluorescent dissolved organic matter (FDOM) in the Nakdong River Estuary, Korea. Biogeosciences 2018, 15, 1115-1122. [CrossRef]

48. Hood, E.; Gooseff, M.; Johnson, S.L. Changes in the character of stream water dissolved organic carbon during flushing in three small watersheds, Oregon. J. Geophys. Res. Space Phys. 2006, 111. [CrossRef]

49. Yang, L.; Guo, W.; Chen, N.; Hong, H.; Huang, J.; Xu, J.; Huang, S. Influence of a summer storm event on the flux and composition of dissolved organic matter in a subtropical river, China. Appl. Geochem. 2013, 28, 164-171. [CrossRef]

50. Murakami, M.; Sato, N.; Anegawa, A.; Nakada, N.; Harada, A.; Komatsu, T.; Takada, H.; Tanaka, H.; Ono, Y.; Furumai, H. Multiple evaluations of the removal of pollutants in road runoff by soil infiltration. Water Res. 2008, 42, 2745-2755. [CrossRef] [PubMed]

51. Lee, J.; Lee, S.; Yu, S.; Rhew, D. Relationships between water quality parameters in rivers and lakes: BOD5, COD, NBOPs, and TOC. Environ. Monit. Assess. 2016, 188, 252. [CrossRef]

52. Zhang, Y.-L.; Yang, L.-Y.; Qin, B.-Q.; Gao, G.; Luo, L.-C.; Zhu, G.-W.; Liu, M.-L. Spatial distribution of COD and the correlations with other parameters in the northern region of Lake Taihu. Huanjing Kexue 2008, 29, 1457-1462. [PubMed]

53. Zhao, Q.; Mao, W. The Distribution of Phytoplankton in Yanming Lake Wetland and Its Response to Water Quality Characteristics. Ecol. Environ. Sci. 2020, 29, 1654-1661.

54. Geng, M.; Niu, Y.; Liao, X.; Wang, K.; Yang, N.; Qian, Z.; Li, F.; Zou, Y.; Chen, X.; Deng, Z.; et al. Inter-annual and intra-annual variations in water quality and its response to water-level fluctuations in a river-connected lake, Dongting Lake, China. Environ. Sci. Pollut. Res. 2021, 28. in press. [CrossRef]

55. Li, F.; Qiu, Z.; Zhang, J.; Liu, C.; Cai, Y.; Xiao, M.; Zhu, L. Temporal variation of major nutrients and probabilistic eutrophication evaluation based on stochastic-fuzzy method in Honghu Lake, Middle China. Sci. China Ser. E Technol. Sci. 2019, 62, 417-426. [CrossRef]

56. Han, J.; Bae, Y.-J.; An, K.-G. Spatial and Temporal Variability of Water Quality in Geum-River Watershed and Their InfluInfluences by Landuse Pattern. Korean J. Ecol. Environ. 2010, 43, 385-399.

57. Qi, W.; Lu, S.; Yang, L. Relationship between removal and transformation of macromolecular weight organics during water supply treatment process by contrasting COD and CODMn. Technol. Water Treat. 2006, 32, 39-42.

58. Jia, L.; Jin, L.; Wan, Y. Research on the Correlation between COD_(Cr) and COD_(Mn) in Sewage Wastewater in Huaihe River Basin. Water Resour. Prot. 1998, 4, 24-27.

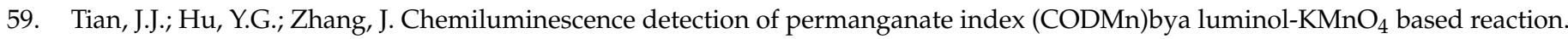
J. Environ. Sci. 2008, 20, 252-256. [CrossRef]

60. Dormann, C.F.; Elith, J.; Bacher, S.; Buchmann, C.; Carl, G.; Carré, G.; Marquéz, J.R.G.; Gruber, B.; Lafourcade, B.; Leitão, P.J.; et al. Collinearity: A review of methods to deal with it and a simulation study evaluating their performance. Ecography 2013, 36, 27-46. [CrossRef] 
61. Strobl, C.; Boulesteix, A.-L.; Kneib, T.; Augustin, T.; Zeileis, A. Conditional variable importance for random forests. BMC Bioinform. 2008, 9, 307. [CrossRef]

62. Tyralis, H.; Papacharalampous, G.; Langousis, A. A Brief Review of Random Forests for Water Scientists and Practitioners and Their Recent History in Water Resources. Water 2019, 11, 910. [CrossRef]

63. Zhang, C.; Ma, Y. Ensemble Machine Learning: Methods and Applications; Springer Science \& Business Media: Berlin/Heidelberg, Germany, 2012; 329p.

64. Diaz-Uriarte, R.; de Andres, S.A. Gene selection and classification of microarray data using random forest. BMC Bioinform. 2006, 7, 3. [CrossRef]

65. Yu, H.X.; Luo, X.; Ma, L.; Tan, W. Effects of the Constructed Wetland on Dissolved Organic Matter Properties in the Drainage Channel of Domestic Sewage Treatment Plant in Winter. In Proceedings of the 2nd International Conference on Civil Engineering, Environment Resources and Energy Materials, Changsha, China, 18-20 September 2020.

66. Murphy, K.R.; Ruiz, G.M.; Dunsmuir, W.T.M.; Waite, T.D. Optimized Parameters for Fluorescence-Based Verification of Ballast Water Exchange by Ships. Environ. Sci. Technol. 2006, 40, 2357-2362. [CrossRef]

67. Gu, Z.P.; Chen, W.; Wang, F.; Li, Q. Transformation and degradation of recalcitrant organic matter in membrane bioreactor leachate effluent by the O-3/ $\mathrm{H}_{2} \mathrm{O}_{2}$ process. Environ. Sci. Water Res. Technol. 2019, 5, 1748-1757. [CrossRef]

68. Peleato, N.M.; Sidhu, B.S.; Legge, R.L.; Andrews, R.C. Investigation of ozone and peroxone impacts on natural organic matter character and biofiltration performance using fluorescence spectroscopy. Chemosphere 2017, 172, 225-233. [CrossRef] [PubMed]

69. Yan, C.; Sheng, Y.; Ju, M.; Ding, C.; Li, Q.; Luo, Z.; Ding, M.; Nie, M. Relationship between the characterization of natural colloids and metal elements in surface waters. Environ. Sci. Pollut. Res. 2020, 27, 31872-31883. [CrossRef] [PubMed]

70. Sakamoto, T. Incorporating environmental variables into a MODIS-based crop yield estimation method for United States corn and soybeans through the use of a random forest regression algorithm. ISPRS J. Photogramm. Remote Sens. 2020, 160, 208-228. [CrossRef]

71. Huber, V.; Wagner, C.; Gerten, D.; Adrian, R. To bloom or not to bloom: Contrasting responses of cyanobacteria to recent heat waves explained by critical thresholds of abiotic drivers. Oecologia 2012, 169, 245-256. [CrossRef] [PubMed]

72. Marcinek, S.; Santinelli, C.; Cindric, A.M.; Evangelista, V.; Gonnelli, M.; Layglon, N.; Mounier, S.; Lenoble, V.; Omanovic, D. Dissolved organic matter dynamics in the pristine Krka River estuary (Croatia). Mar. Chem. 2020, 225, 103848. [CrossRef] 